Neues Verfahren der Saftgewinnung aus Runkelrïben. 147

\begin{tabular}{|c|c|c|}
\hline $\begin{array}{l}\text { Betriebs- } \\
\text { jahre. } \\
1850\end{array}$ & $\begin{array}{c}\text { Zahl der } \\
\text { activen Fabriken. }\end{array}$ & $\begin{array}{l}\text { Verarbeitete Rüben } \\
\text { Zollcentner. }\end{array}$ \\
\hline $\begin{array}{l}1800 / 51 \\
1851 / 52\end{array}$ & $\begin{array}{l}184 \\
234\end{array}$ & $\begin{array}{l}14,124,508 \\
18,289,901\end{array}$ \\
\hline $1852 /_{53}$ & 238 & $21,717,096$ \\
\hline $1853 i_{54}$ & 227 & $18,469,889$ \\
\hline $18^{54} / 55$ & 222 & $19,188,402$ \\
\hline $18^{55} / 56$ & 216 & $21,839,798$ \\
\hline $18^{56} / 57$ & 233 & $27,551,207$ \\
\hline $18^{57} / 58$ & 249 & $28,915,133$ \\
\hline $1858 / 59$ & 257 & $36,668,577$ \\
\hline $1859 / 60$ & 256 & $34,399,317$ \\
\hline $1860: 61$ & 247 & $29,354,031$ \\
\hline $18^{61} /_{62}$ & 247 & $31,692,394$ \\
\hline $1862 / 63$ & 247 & $36,719,258$ \\
\hline$\left.18^{63}\right|_{64}$ & 253 & $39,911,520$ \\
\hline
\end{tabular}

Durchschnittlich wurden demnach in obiger Zeitperiode jäbrlich 27,102,915 Ctr. Rüben für die Zuckerfabrikation verwendet. Man rechnet, dass $11^{1 / 2}$ Ctr. Rüben einen Centner Rohzucker oder 82 Pfd. (7,13 Proc.) Raffinade geben. Somit würden im letzten Jahre 2,845,865 Zollcentner Raffinade im Zollvereine erzeugt worden sein, die nach dem Fabrikpreise einen Werth von 85,377,000 FI. darstellen. (In Oesterreich betrug die Production an Rübenzucker etwa 1,487,166 Zollcentner.) Der gegenwärtige Bedarf an Zucker im Zollvereine wird durch die inländische Fabrikation gedeckt. (Dingl. polyt. Journ. Bd. 176.)

$B$.

\title{
Neues Verfahren der Saftgewinnung aus Runkelrüben;
}

$$
\text { von } R \text {. de Massy. }
$$

Der von der Rübe kommende Rübenbrei wird mit 7 Proc. Kalk gemischt auf $50-60^{\circ}$ erhitzt, dann in ein geschlossenes konisches Gefäss, und hierauf in den cigentlichen Saftgewinnungsapparat gebracht. Dieser besteht aus einem eisernen, vertical stehenden, durchlöcherten Blechcylinder und einem inneren, etwas engeren Cylinder, ebenfalls aus Blech. Um letzteren befindet sich ein Kautschukfutter, die inneren Wände des äusseren Cylinders sind mit Leinwand gefüttert. In den Hohlraum zwischen beiden wird der Brei mittelst Dampfdruck getricben, der Saft dringt durch die Leinwand. Zuletzt lässt man hydrostatischen Druck zwischen dem inneren Cylinder und dem Kautschukfutter wirken, und drückt so den Brei vollkommen 
aus. Der trockene Riickstand beträgt nur 11 Proc. vom Gewichte der Rüben. (Polytechn. Journ. Bd. 180). S. 396. 1866.)

$B$.

\section{Der condensirte Rübendampfsaft (Brüdenwasser) der Dünnsaftapparate}

Theilen :

enthält nach einer Analyse von Stammer in 10,000

$0,14-0,16$ Th. organische Substanzen,

$0,05-0,02$ Th. unorganische Substanzen,

$0,59-1,87 \mathrm{Th}$. Ammoniak.

Die Polarisation des aut ${ }^{\prime}{ }_{200}$ eingedampften Wassers war 0 ; die Reaction deutlich sauer, walırscheinlich von Fettsäure; hieraus dürfte der Schluss zu ziehen sein, dass der Anwendung dieses vollkommen zuckerfreien Wassers nach dem Abküblen und allenfalls unter Zusatz von sehr geringen Mengen Kiilk ouer gewöhmlichem Wasser, irgend welche Bedenken nicht entgegenstehen, und dass diese Anwendung die Melassebildung erheblich vermindern werde. (Dingl. polyt. Jou'n. Bd. 177.) B.

\section{Die Fabrikation der Zuckercouleur}

ist bis jetzt immer noch als Geheimniss angesehen worden, welches nun von Assmuss aufgeschlossen worden ist. Das Wesentliche derselben besteht darin, dass man Zucker unter Zusatz von Soda, Aetznatron, Pottasche oder Aetzkali, oder, wie bei der Darstellung der Essigcouleur, von kohlensaurem Ammoniak in einem metallenen Gefäss über freitu Feuer so lange kocht, bis sich der Zucker in eine dunkelbraune, fast schwarze, aufgeblähte Masse verwandelt hat, worauf eine bestimmte Menge kochenden Wassers allmälig zugegeben wird. Der Alkalizusatz bezweckt die Farbe kräftiger, d. h. intersiver dunkler zu machen, aber auch die kleine Menge Humussäure, die sich beim Kochen bildet, in Autlösung zu erhalten und so eine Trübung der Coulcur zu verhindern. Beim Kochen kann das Feuer anfings, dimnit der Zucker schneller schmilzt, ziemlich stark sein und so lange verstärkt gehalten werden, als der Zucker noch eine helle oder fuchsrothe Farbe zeigt; sobald er stechende graue Dämpfe zeigt, muss das Feuer gemässigt und die Masse im Kessel beständig umgerübrt werden. Beim Kochen der Essigcouleur wird 